\title{
The Emergence of Outreach Ambassador Role Identities in Undergraduate Engineering Students
}

\author{
Joanna Garner ${ }^{1}$, Christine Haas², Michael Alley ${ }^{3}$, and Avi Kaplan ${ }^{4}$
}

${ }^{1}$ The Center for Educational Partnerships, Old Dominion University; ${ }^{2}$ Engineering Ambassadors Network; ${ }^{3}$ Engineering, Pennsylvania State University; ${ }^{4}$ Educational Psychology, Temple University

Keywords: Engineering Outreach, Ambassador, Identity, Professional Development, Undergraduate Students

Publication Date: Monday, December 17, 2018

DOI: https://doi.org/10.15695/stem/v1i1.27

\begin{abstract}
One common form of outreach by colleges of engineering is the ambassador program, whereby students interact with middle and high school audiences in an effort to promote STEM-related career choices. Although the impact of such programs on K-12 students' knowledge and attitudes has been examined, less is known about the impact on the ambassadors themselves. In this research study, we use multiple case study methodology to understand the development of the ambassador role and its emergence at an initial workshop in which undergraduate students learn to craft and deliver engineering-related outreach talks. Narrative data from interviews with a purposefully diverse sample of six participants allowed us to analyze emerging ambassador role identities using the Dynamic Systems Model of Role Identity (Kaplan and Garner, 2017). Findings address three questions: (1) How do individuals' existing role identities inform the motivation to become an ambassador? (2) How did the role of workshop participant shape the development of the ambassador role? (3) Which features of the training workshop promoted the formulation of an engineering ambassador role identity? Analyses revealed that the ambassador role identity originates from and was very much aligned with components of students' other, pre-existing role identities. Also evident was a bridging sub-role of presenter, which was anchored in the action possibility of high quality technical communication. Theoretical and practical considerations for preparing undergraduate engineering students to take on an ambassador role are considered.
\end{abstract}

\section{INTRODUCTION}

Pre-college outreach has become an increasingly popular activity for undergraduate students (Orsak, 2003; Moskal and Skokan, 2011). Involvement varies in scope from single events to summer camps and even year-long engineering design competitions (After School Alliance, 2011; Stake and Mares, 2001). Underlying themes for such events include the variety of career opportunities for engineers, the societal benefits of engineering related work, and the need for STEM participation by historically underrepresented groups (Anagnos et al., 2014). Events can educate the public in these and other messages that can help to change local conversations about the appeal of science and engineering (NAE, 2008) and introduce future students to university campuses and degree programs.

One particular outreach format is the ambassador program, in which groups of undergraduate students deliver in-class presentations and hands-on activities to middle and high school students in order to illustrate the nature, impact and possibilities of engineering. Such visits can increase the audience's knowledge, interest and identification with science and engineering as well as awareness of and interest in STEM-related degrees and career options (Nadelson and Callahan, 2011; Molina-Gaudo et al., 2010; Habash and Surtamm, 2010; Sahin, 2013; Smaill, 2010; Wei and Wonch Hill, 2018). However, little is known about the ways in which participation in an ambassador outreach program might act as a professional development vehicle for the undergraduate student.

In this article, we build on previous research that has explored students' motivations for outreach participation and explore the topic of outreach participation from the unique perspective of students' role identity development as ambassadors. This perspective allows us to examine students' self-perceptions, goals, beliefs, and possibilities for action in relation to their perceptions of themselves as ambassadors for their chosen field and representatives of a college or university. Relatedly, since ambassadors often go through an initial training period where they learn about specific pro-engineering messages from Changing the Conversation (NAE, 2008) including "engineers help shape the future," "engineering is essential to our health, happiness and safety," "engineers make a world of difference," and "engineers are creative problem solvers" - as well as strategies for presenting information about science and engineering in interesting 
and relevant ways for middle and high school audienceswe were also interested in gaining an understanding of the context and conditions in which the ambassador role begins. Insights derived from this research might then be used to design and evaluate ambassador programs and monitor them for the presence of identity-based outcomes as well as the effectiveness of solution-oriented messages that can tackle the problem of misconceptions about the field of engineering.

Students' motivation to participate in engineering outreach. As a first step toward considering how students come to think of themselves as ambassadors for their field, it is important to consider their motivation to participate in a time-consuming activity that typically offers little financial reward. Some researchers have proposed that students may be attracted to organizations because they convey values that align with their personal and professional goals (Bergeson et al., 2014; Lamb, 2010; Serpe and Stryker, 1987). Therefore, messages conveyed by outreach programs such as the application of engineering to solving the world's problems (UNESCO, 2010), the need for diversity among the STEM workforce (President's Council, 2010), and the need for creativity and problem solving within engineering (NAE, 2008), may resonate for students who consider these values to be foundational to their motivation for a professional career. For example, in one qualitative study of undergraduate members of the ambassadorial group Engineers without Borders (EWB), Litchfield and Javernick-Will (2015) revealed that members' professional goals tended to align engineering with social justice, humanitarian work, community development, and environmental sustainability. Similarly, three quarters of the respondents in a survey-based study of undergraduate engineering ambassadors by Anagnos et al. (2014) indicated that ambassador participation was commensurate with students' personal goals of making a difference in their communities. In contrast, just 20 percent of respondents reported involvment with ambassadorship as a means of doing well in their studies, and only 6 percent expressed interest in the program as a way to explore options for a future career in engineering.

Some studies have noted that engineering students who endorse social engagement and social justice within their personal and career goals tend to be diverse in their cultural and racial backgrounds (Litchfield and Javernick-Will, 2015; Tate and Linn, 2005). These students are also more likely to become involved in service and advocacy activities at the university level, perhaps because these activities are aligned with their own personal values and experiences (Lichtinger and Kaplan, 2011). Set within the national context of a need to increase diversity among engineers (President's Council, 2010), such studies hint at the potential for harnessing a diverse group of students' pre-existing interests and value commitments in order to engage future generations of STEM professionals. However, little is known about how such commitments intersect with students' experiences during the context of pre-visit training experiences.

A small number of studies have focused on the perceived impact of outreach participation. In a retrospective interview study of 19 engineering students, Bergeson et al. (2014) found that students attributed great meaning to interactions with other professionals and peers throughout the program. Interactions were interpreted as opportunities to observe others as role models and gatekeepers of professional actions, skills and behaviors. Students reported specific gains in their ability to connect engineering concepts with real world topics, and their confidence to communicate with non-expert audiences. They also reported gains in self-perceptions as engineers and purveyors of engineering content, personal value of an anticipated career in engineering, and satisfaction in raising others' interests in engineering careers. Bergeson and colleagues interpreted these perceived benefits as examples of ways in which outreach participation influences students' overall self-definitions as engineers and representatives of the field of engineering. Students' personal affiliation and ascribed value of the field of engineering also suggested that ambassadorial activities impacted their commitment to engineering (Erikson, 1968; Serpe and Stryker, 1987). Taken together, these studies point to ambassadorship as a potential mechanism for satisfying and fostering motivational aspects of students' early conceptualizations of their professional selves.

\section{A theoretical framework for studying outreach ambas-} sadorship. Recently, researchers have focused on understanding the development of science and engineering identities, or perceptions of one's self as a scientist or engineer, as factors that influence STEM persistence and attrition among historically underrepresented groups of students (Hazari et al., 2013; Papafilippou and Bentley, 2017; Steinke, 2017). Through identity-based perspectives on students' motivation, such as possible selves (Marcus and Nurius, 1986), researchers have established that one's sense of who one is and who one can (or cannot) become within a given field of study, career path, or life course, can act as a substantive source of motivated action (Allie et al., 2009; Oyserman et al., 2004; Nino, 2013; Nystrom, 2009). However, few scholars have investigated the potential multiplicity of STEM-related identities that may emerge over the time course of an undergraduate student's period of enrollment at an institution, and how these may be related to specific experiences or opportunities such as ambassadorship. Moreover, researchers have not examined the cognitive and motivational processes that might occur within individual students as they make meaning from degree-relevant, co-curricular contexts that can influence the formation of a STEM-infused self-concept that leads to a future orientation of STEM professional.

With this in mind, our search for a theoretical framework 
through which we could construct an understanding of the cognitive and motivational processes involved in the development of students' sense of self as an engineering outreach ambassador led us to role identity theory. Role identity is a conceptualization about one's role in a given social context (Burke, 2006; Stryker and Burke, 2000), and it can be used to explain why individuals vary in their membership of, role within, and commitment to, particular organizations (Penuel and Wertsch, 1995). According to this theory, behavior is in part determined by one's role identity or conceptualization of the role one plays in a given situation. Roles can be formal such as engineer, professor, or ambassador, or informal such as friend, neighbor, or host. Roles may be more or less salient in different contexts or situations, and exist within the individual's overall identity system (Burke, 2006). Individuals seek coherence and alignment within and between roles, and may abandon roles that generate conflict among self-perceptions, beliefs, goals or actions (Burke and Harrod, 2005; McAdam and Paulsen, 1993; Reitzes and Mutran, 1995). Because these processes occur throughout life, including the period during which individuals attend college (Burke and Reitzes, 1991; Serpe and Stryker, 1987), convening groups of students and training them to become ambassadors offers the opportunity to explore role identity development in undergraduates.

Our perspective acknowledges that role identities may fluctuate and may even be co-activated within a given situation, such as when a student participates in a training workshop as a participant but retains their role identity as an ambassador for their school or a student in a particular degree program. Therefore, although the ambassador role is specific to a particular situation, it exists in conjunction with others such as an undergraduate student, young adult, and engineer-in-training. Therefore, any understanding of the role of ambassador must be understood in relation to individuals' other roles, and the beliefs and values associated with them.

The Dynamic Systems Model of Role Identity. The present study employs the Dynamic Systems Model of Role Identity (DSMRI; Kaplan and Garner, 2017), which specifies role as the primary unit of analysis and leverages role as a meaningful organizing frame for individuals' narrative statements about their experiences. A schematic depiction of the DSMRI is shown in Figure 1.

The DSMRI holds that the core structure of a role identity consists of four interacting and mutually influential components that are situated within a social context. One component is self-perceptions - aspects of the self within a particular role including self- described characteristics, abilities, preferences, interests, and knowledge. A second component is purpose and goals - expressions of a person's purpose for action in the role and the goals that might relate to that purpose. A third component is beliefs - knowledge and concep- tions that are stated as being true about the world or about a domain, such as engineering. The fourth component is future-oriented action possibilities - plans, intentions, strategies, and behaviors that the individual feels are possible or impossible in the role. These four intra-individual components emerge continuously through social interactions in different contexts. The components interact in a dynamic fashion among themselves, and with analogous components that belong to other important roles of the person. The interdependent nature of the components can be characterized in terms of the degree of alignment or lack thereof, and the degree to which the role identity is in harmony or otherwise integrated with other roles. A given situation can accentuate the prominence of one or more roles, and may cause the individual to choose among competing roles (e.g. student versus ambassador). In this sense, the model combines the previous emphases on individual and social origins of role identity and assumes that any given role identity will exist within a network of such roles.

The four components interact to form the basis for motivated decision making and action in a given role in a particular situation. For example, a student might have a particular set of beliefs about the field of engineering such as it being misperceived by the public, or a set of beliefs about others, such as the capacity of women and girls to participate and contribute to engineering fields. These beliefs might align with the student's personal and professional goals of becoming a professional engineer who can reach out to others about the nature of the field and the importance of broadening participation. The student might possess a self-perception as a champion of both pro-social applications of engineering activities and as someone who has overcome the odds to become a female engineering student. Her action possibilities might include joining the engineering ambassadors pro-

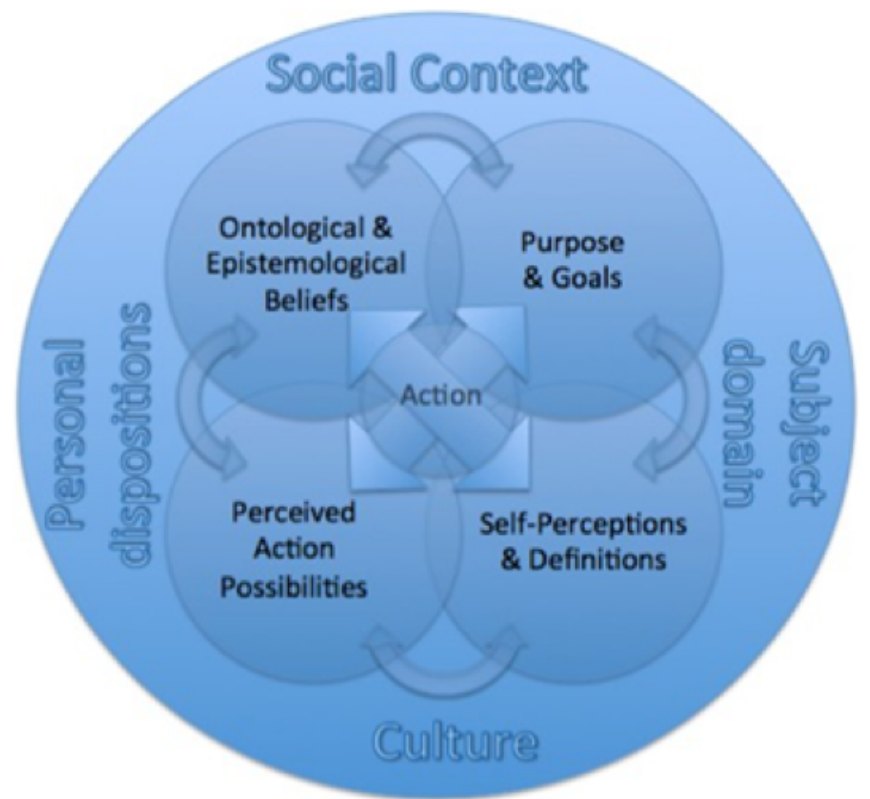

Figure 1. The Dynamic Systems Model of Role Identity 
gram in order to conduct outreach visits to middle and high schools to share her knowledge and passion for engineering. Taking action as an ambassador might in turn impact her beliefs about how and why individuals decide to stay or leave the STEM pipeline in school. Actions might also impact her self-perceptions about her capacity to influence and lead others, thus strengthening her professional goals of achieving a leadership and mentorship position in engineering career. This might lead to further action possibilities of becoming a senior ambassador, and perhaps exploring engineering management as a future career goal.

Several studies have explored the utility of the DSMRI as a theoretical framework for understanding young professionals' role identity development. In one study, Gunersel and colleagues (Gunersel et al., 2016) employed the DSMRI to examine changes in graduate students' role identities as teachers within the context of a semester long course about teaching. The researchers noted individual variation in the degree of change within role identity components, but also found that students' final role identity configuration was strongly related to their initial conceptualization of self within the role of teacher at the start of the training. In another study of college students' role identity change, Heffernan (2016) used the DSMRI to study pre-service teachers. Through an analysis of reflective writing assignments, she found that varying degrees of change in students' role identity components emerged from the interplay between initial role identities, the course activities, and the social context. Finally, in a multiple case study of teachers in a professional development setting, Hathcock (2014) echoed the findings of both Gunersel et al. (2016) and Heffernan (2016). Interviews of six participants before, during and after a professional development workshop revealed strong connections between initial and final role identity configurations, and highlighted that common experiences can impact individuals in different ways, but also showed thematic connections between participants' post-event action possibilities and the overall goals of the training event.

Together, these studies informed our expectations because they demonstrate that participants' experiences of a training workshop manifest through the interplay between particular social contexts and the content and relations among participants' self-perceptions, goals, beliefs, and action possibilities. In addition to using the DSMRI to gain insights into students' role identities as ambassadors, this is the first study to apply the model to the issue of recruiting and retaining undergraduate students for conducting STEM outreach.

\section{OUR STUDY}

Our study used a training event as a context for studying the emergence of the ambassador role. We proposed that participation in the workshop, which included a great deal of communication skills training and plentiful opportunities to interact with students and faculty from their own and other institutions, would call upon aspects of students' pre-existing role identities. Our objective was to understand how, from among a student's other roles, and in the context of an ambassadors' training event, the ambassador role might emerge. Our research questions took into account the findings of prior research in which the DSMRI has been used to understand participants' experiences of a professional development setting. They were threefold:

(1) How do individuals' existing role identities motivate them to become an ambassador? We predicted that the students' prior self-perceptions and personal values would align with those of the engineering ambassadors' mission, which includes the communication of messages from Changing the Conversation (NAE, 2008).

(2) How did the role of workshop participant shape the development of the ambassador role? We anticipated that students would manifest multiple role identities during their narrative describing experiences at the training workshop. In addition, components of an engineering ambassador role identity may emerge within the context of additional, salient roles throughout the workshop, such as undergraduate student, representative of a particular college, presenter, and/or workshop participant.

(3) Which features of the workshop emerge as the most powerful experiences for triggering the formulation of an engineering ambassador role identity? A new role might become evident to an individual as new possibilities for action are generated, and when such possibilities afford membership within a social group. Therefore, we predicted that aspects of the workshop that promote a sense of social group identity as an ambassador, including the key event of delivering an outreach presentation to an audience of other ambassadors, would emerge across cases as powerful experiences that would populate the contents of the ambassador role identity.

\section{METHODS}

Design. Qualitative research designs provide a means for in-depth examination, deconstruction, and reconstruction of phenomena-in-context (Baxter and Jack, 2008). The case study approach is based on a constructivist paradigm that recognizes and emphasizes individuals' subjectivity and the social construction of reality (Yin, 2003). Within qualitative research, constructivism embraces the opportunity for participants to share their stories, and treats these as representations of the participants' realities.

Case study is an appropriate choice for answering 'how' and 'why' questions in cases where the contextual conditions are relevant to the phenomenon being studied. In this case, we chose to use a single case study with embedded 
units (individual students) because of the common context experienced by the participants (Yin, 2003). The study was conducted with an instrumental rather than an explanatory purpose in mind (Stake, 1995), meaning that we were interested in gaining descriptive insights into a particular phenomenon - the development of students' ambassador role identities. Our sampling method sought purposefully diverse cases, where diversity was operationalized as criteria by which we would expect the phenomena of interest to vary such as gender, ethnicity, subject matter specialism, prior experience in the role, etc. The aim of this approach is not to generate a prototypical or average case from which to extrapolate to other samples, but instead to generate a rich understanding of the phenomenon using a staged approach of case analysis followed by theme generation across multiple cases (Creswell, 2013; Moustakas, 1994).

Context. The context for the study was a three-day training event that was focused on the development of brief, high quality, engaging outreach presentations aimed at middle or high school audiences. Presentations were required to convey information about engineering concepts and one or more messages drawn from the NAE's Changing the Conversation report (NAE, 2008). For example, an ambassador might choose to prepare their 8 minute talk on the topic of $3 \mathrm{D}$ printing. In addition to teaching the audience about what $3 \mathrm{D}$ printing is and how it works, the ambassador might include reference to the applications of 3D printing that align with the Changing the Conversation message that engineers contribute to the health and wellbeing of society, such as 3D printing of prosthetic limbs. The ambassador learns to use principles of storytelling and effective technical communication skills to convey a message designed to capture the imaginations of young students while also leveraging their knowledge of science and engineering concepts from the school curriculum.

Workshop format. Approximately 150 new and returning ambassadors attended the event, as well as faculty advisors from each of the eight participating universities, two senior facilitators, and a research team that included the current authors. On the first full day of training, participants engaged in whole group instruction where they were introduced to the mission and purpose of the engineering ambassadors program, and were exposed to an advanced strategy for an outreach presentation. This presentation strategy was significantly different from what most ambassadors had used or even seen, but is more effective at communicating technical content than traditional approaches (Garner and Alley, 2013). Students had time to work on their outreach presentations under the guidance of returning (senior) ambassadors. On the second day, once formal instruction ended, students formed breakout groups and delivered their presentations twice in small group critique sessions in which they received feedback from senior ambassadors. During the evening, students once again were given time to work on their presentations. On the third day, presentations were delivered in a small group environment called the "showcase." The workshop ended with concluding remarks by the event's primary facilitators.

Participants. Six first-time attendees were included in the study. The sample was purposefully diverse and reflected differences in gender ( $\mathrm{n}=3$ male, $\mathrm{n}=3$ female); ethnicity $($ Hispanic $/$ Latino $=1$, African American $=1$, Caucasian $=4$ ) school type (large, public state universities $=3$, midsized public state university $=2$, small, private faith based college $=1$ ); engineering major (electrical engineering $=1$, bio engineering $=1$, environmental engineering $=1$, general engineering $=2$, material science engineering $=1$ ); and maturity of ambassador program (existing program $=3$, new program $=3$ ). All but one participant was new to the program - this one participant was beginning a second semester of participation at the home institution, but was attending the workshop for the first time. The demographic statistics of the sampled subset was comparable to their semester standing as traditional age college students and also comparable to the broader group of workshop attendees. Registration data revealed that $57 \%$ of the 159 registered attendees were female, and $43 \%$ were male. Regarding ethnicity, $8 \%$ were African American, 3\% were Asian or Asian/Caucasian, 11\% were Hispanic/Latino/a, $65 \%$ were Caucasian, and $4 \%$ indicated "Other." Most (79\%) of the students were first time attendees or "junior ambassadors," with the majority entering either their freshman (35\%) or junior (58\%) year in school.

To select participants, the first author, acting in the role of researcher, chose two critique sessions at random from the list. Within these sessions, the researcher then observed students as they made their initial presentations and gave and received feedback to others. Students' names were then compared to the registration database to verify self-identified gender, ethnicity, school type, and major. From this subsample, a diverse group of six students was verified. After the workshop concluded, students in these sessions were contacted via e-mail to request a 30 minute phone interview. A summary of participants' characteristics is provided in Table 1 .

\section{PROCEDURE}

After providing informed consent, participants were interviewed by telephone within two weeks of the workshop end date. The interview protocol was semi-structured and included a series of open-ended questions with follow-up questions permitted for clarification purposes. Participants were asked to provide background about themselves and 
Table 1. Summary of Participant Characteristics

\begin{tabular}{ll}
\hline Participant & \multicolumn{1}{c}{ Demographic Characteristics } \\
\hline Alex & Male, Caucasian, Sophomore, Engineering with a minor in Robotics \\
Fisher & Male, Hispanic, Sophomore, Material Science Engineering \\
James & Male, Sophomore, Caucasian, Electrical Engineering \\
Carla & Female, Senior, Caucasian, Environmental Engineering \\
Hope & Female, Freshman, African American, Bioengineering \\
Martha & Female, Sophomore, Caucasian, Engineering \\
\hline
\end{tabular}

their decision to become an engineering major and their decision to attend the workshop. Prompts included "How was it that you decided to become an engineering major?" "What do you see yourself doing in the future?" "How did you choose [university] engineering program?" Each participant was then asked to give a re-telling of their experiences at the workshop, including highlights, challenges or dilemmas, and events or experiences that were particularly meaningful. Prompts included "Please tell me about your experiences of the workshop. What were some of the biggest highlights for you?" and "What were some challenges or dilemmas you faced?" The interview concluded with a question about how the participant viewed his or her role within their college's chapter of the organization once the school year was underway. Prompts included "Moving forward into the school year, how do you see yourself in the role of engineering ambassador?" Interviews were audio-recorded and transcribed. Identifying names and institutions were removed and pseudonyms were assigned.

Coding. A combination of model-guided (deductive) and data-driven (inductive) coding methods were used (Zhang and Wildemuth, 2009). After establishing consensus regarding code categories, interviews were coded by the first author. The fourth author, who was also present at the workshop, acted as an auditor. The fourth author read the transcripts and examples of particular codes, reviewed the case summaries and provided guidance drawn from knowledge of the transcripts and context of the workshop as well as knowledge of the theoretical model, and reviewed the cross-case analysis. The model-guided coding scheme was developed from the DSMTRI by the first two authors. It represented an adaptation from codebooks utilized in other studies examining role identity development and change (Garner et al., 2016; Kaplan and Garner, n.d.). Thorough reading of the six transcripts was used to establish and finalize the codebook as it pertained to the content of the interview.

The coding scheme treated role as the primary unit of analysis. Roles and the components of each were identified initially by close reading of each transcript. In all six cases, the following roles emerged: Undergraduate Engineering Student, including future professional or engineer; Workshop Participant; and Engineering Ambassador, including a bridging sub-role of presenter that, depending on context, referred to presenting within the conference or in other settings. Within each role, statements were coded at the sentence level as representing components of a particular role identity (Table 2). Common components included self-perceptions, purpose and goals, beliefs and assumptions, and action possibilities.

In addition to coding at the role identity component level, transcripts were examined for statements relating to the social context of the workshop. Statements were highlighted and excerpted from the transcript if they referred to interactions with students from the home school or other schools, interactions with mentors or facilitators, and observations of characteristics of other students or the programs that they represented. This process was to facilitate the discovery of how social contexts might be of relevance to role development.

Analysis of Individual Cases. A summary table was constructed for each individual participant to organize within-case analyses. Columns of the table indicated roles and rows corresponded to role identity components. Statements that had been coded by role and component in the interview transcript were then placed into the cells of the table to provide an organized matrix from which alignments and tensions among components and roles could be derived. The final row of the table contained a short summary of statements included within each role, and highlighted areas of alignment or tension between components. Thereafter, a synthesis statement was created in which alignment, integration, and/or tension among the three roles were highlighted. The table contents and synthesis statements were compared to the interview transcript to ensure that the findings were congruent with the participant's apparent intent.

Cross-Case Analysis. Cross-case analysis was guided by the three research questions: how individuals' existing role identities provided fodder for the motivation to become an ambassador, how the role of workshop attendee shaped the development of the ambassador role, and which features of the workshop seemed to be most salient for promoting the ambassadorial role. This step in the analysis involved crosscase review of the individual participants' role-by-compo- 


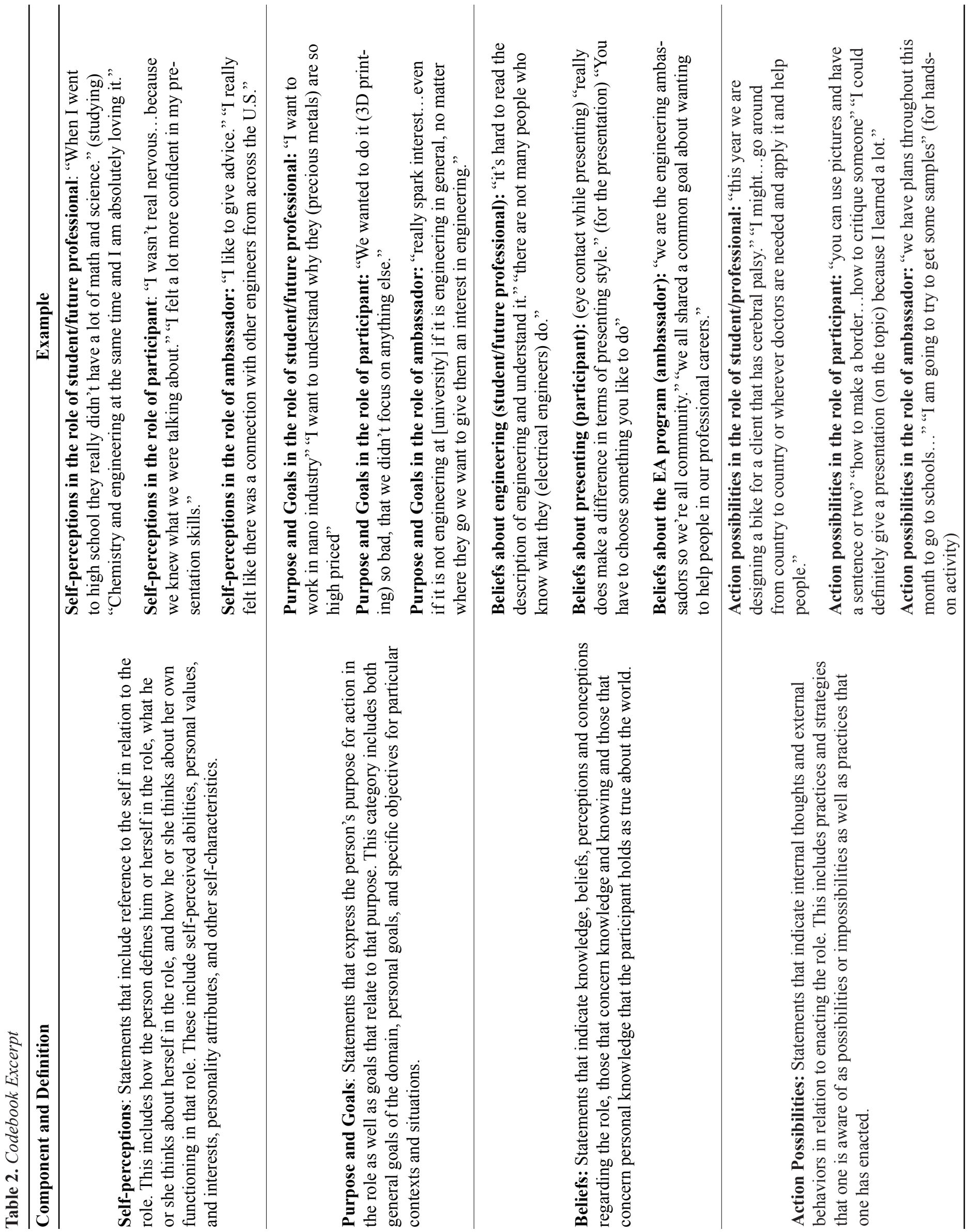


nent matrices and verification of the context and content of statements by referring to the individual level data tables and original transcripts.

To respond to the first research question, How do individuals' existing role identities inform the motivation to become an engineering ambassador?, we analyzed issues and themes in the "Problem Statement" and "Solution Messages" sections of the Changing the Conversation documents (NAE, 2008). Problems included the following: engineering only being for those who love or who excel in math and science; the public's lack of knowledge or misunderstanding about what engineering is and what engineers do; and the lack of diversity from women and other represented groups. Solution messages to counter these problems included the following: emphasizing that engineers impact people's lives in meaningful ways; messages about how engineers help shape the future; the idea that engineers solve problems; and the statement that engineers contribute to our health, happiness and safety (NAE, 2008). These ideas and themes are integral to the mission of the ambassador organization and were mentioned during the direct instruction portion of the workshop. Although retrospective, we sought the incidence and degree to which themes bore significance on students' goals and purposes for becoming an engineer and joining the ambassador organization.

To answer the second research question, How did the role of workshop participant shape the development of the ambassador role?, we examined the self-perceptions component of each role identity for each participant, and reviewed statements for evidence that students could imagine themselves in a likely formal role such as a professional communicator or ambassador. We also looked for statements that might reveal continuity between role-related self-perceptions such as undergraduate student, engineering enthusiast, and workshop participant.

We explored the third research question, Which features of the workshop emerged as the most powerful experiences for triggering the formulation of an Engineering Ambassador role identity?, through a two-step process. First, we reviewed data from each case for specific references to particular workshop activities, such as receiving instruction in presentation slide design or presenting in a critique session. Once a list of these had been created for each individual it became apparent that for all six of the cases, the same activities were mentioned albeit in slightly different ways. Thematically, these activities were then grouped into two types: (1) developing and delivering a presentation, which included presentation instruction and critique/showcase opportunities to present, and (2) social aspects of the workshop, which included networking and mentoring from other ambassadors. Individuals were then compared with one another to establish similarities and differences in the ways in which these themes were prevalent in their narratives.

\section{FINDINGS}

In this section, we describe each individual as an embedded unit within the case study, then provide a summary of the analyses to articulate some major themes that were found across cases. Then, we answer the three research questions based on the collective analysis of the interview transcripts, which includes findings that arose from consideration of both the inductive and the deductive, DSMRI-guided analyses.

For each individual, themes and commonalities were manifest in slightly different ways. For example, each participant was able to provide a statement revealing the origin of their interest in engineering and each articulated a goal of pursuing an engineering-related career. These initial self-perceptions and goals revealed aspects of participants' initial role identities as beginning engineers, and served as a starting point for role identity development as workshop participants and beginning ambassadors. Similarly, initial interests in specific topics and beliefs about what would make for a successful presentation in the role of ambassador, influenced their choice of presentation topic. Importantly, students articulated a pro-societal purpose for their engineering careers and their work in the role of ambassadors. These purposes were aligned with both the mission of the organization and the content of the Changing the Conversation messages upon which their presentations were based. After the case summaries, we turn to the findings of the analysis of the transcripts of their experiences at the workshop, which offer insights into the ways in which particular features of the workshop context impacted the development of their role identities as ambassadors.

\section{OVERVIEW OF CASES}

Alex. Alex was a male sophomore student studying for a general engineering degree with a minor in robotics. The interview with Alex revealed alignments between his personal and professional goals of using his skills to "give back" and his university's propensity for doing "a lot of outreach in the community." He spoke positively about the degree structure and perceived philosophy of his university. One example he gave was that for his sophomore year "we are designing a bike for a client that has cerebral palsy. I love projects like that because I am able to use my skills and other fellow peer students can use their skills to help citizens in the community and give back and I really enjoy that aspect of [university name] engineering." His university was participating in the training event for the first time, making him one of the first cohort of ambassadors at his school. Alex described himself as someone with aptitudes in math and science and a longstanding, keen interest in "how things work." When speaking about the most meaningful aspects of the workshop training, Alex stated that he was "proud to be a part of" the creation of a presentation that was "geared towards high schoolers" in 
order to "really get them interested in engineering."

Fisher. Fisher, a male, Hispanic, first generation college student from a large northeastern university with an established ambassador program, told the interviewer that he was initially undecided about his major. Participation in a summer "bridge" program helped him find friends and role models in the engineering programs at his university. After initial exploration in chemical and then civil engineering, Fisher was enrolled in the materials science major. As a college band player, Fisher was happy to integrate his love of music into the outreach presentation he developed at the workshop, which was on the topic of 3D printed musical instruments. Fisher commented on workshop-related gains in his knowledge and skills as a presenter and critical friend for others' presentations, and reported having used his new skills even in the few days between the workshop and the interview. The workshop also provided a context for Fisher to discover his desire to adopt the role of a mentor or teacher within his future as an ambassador or engineer. He articulated that the EA program provides a sense of community and can help others to improve themselves.

James. James, a Caucasian male sophomore at a small northeastern college with an established ambassador program, was pursuing a degree in electrical engineering. His self-described "passion," content knowledge, and area of undergraduate research focused on the topic of organic capacitors, and he integrated this interest into his presentation topic. In his interview, James expressed the belief that engineering, and particularly electrical engineering, are not well received by high school students and are frequently misinterpreted by the public. He did not tie his motivation to pursuing electrical engineering to societal outcomes but he did express a belief that engineering outreach might help economic redevelopment in underprivileged areas around his school. James was concerned about being "ignored" by students during an outreach presentation, but reported that the workshop helped him to overcome this fear. He realized, however, that he suffered from "the curse of knowledge" as a presenter, and found it "really challenging" to create a presentation that would be suitable for a younger, less knowledgeable audience.

Carla. Carla was a female, Caucasian senior from a small, faith-based university with no prior ambassador program. She described herself as being "pretty good" at math and science. Her educational and professional goals included the integration of faith into engineering and the use of her skills for "good." At the time of the interview and entry into the ambassador program, she had already completed a mission trip to Africa to train others on water filtration systems, something she then incorporated into her outreach presenta- tion. Keenly aware of the size difference between her school and some of the other participating schools, Carla appreciated being able to see the possibilities and how "what these big schools are doing in their engineering program that we could be implementing at our school." However, as a graduating senior, she was aware that growing the program would fall to others in the future.

Hope. Hope was a female, African American freshman student studying at a small northeastern state college. She articulated personal reasons to pursue engineering and eventually medicine, with goals of understanding how things work and helping (saving) others within the United States and abroad. Although she worked with a presentation topic that she was initially unfamiliar with, she reported gaining confidence and knowledge in regards to both presentation skills and the content. The social context helped her to gain confidence in presenting and the topic matched her goals of helping communities overseas. Hope understood the goals of the EA program as being to help others overcome misperceptions about engineering, particularly its lack of application to people. She used the term "we" to describe the plans that emerged for future outreach and presentation activities after the workshop had ended.

Martha. Martha was a Caucasian female, sophomore student at a college in the mid-Atlantic region of the United States with no prior ambassador program. Her interests as an engineering student and future engineer were broad, as was her presentation topic area (3D printing). She hoped that this would increase interest and excitement about engineering for a wide audience of students. Martha appreciated both the social context of the workshop and the detailed instruction on presentation techniques, which she believed would be applicable to other areas of her life including coursework. She reported gaining confidence in her public speaking abilities. She found watching the other teams' presentations to be very interesting, and left the workshop feeling that engineering is not just about math and science but about interesting topics and an orientation to help others.

Summary. Three overarching themes arose from our inductive analysis of the six individuals.

1. Beginning ambassadors exhibited pre-existing beliefs and goals that formed part of their role identity as a future engineer, and which were well aligned with the mission, if not the method, of the outreach role for which they were being trained. Even prior to ambassadorship, students' existing self-perceptions and personal and professional goals were aligned with the mission of the organization. The training environment fostered a sense of group membership, which seemed to provide students with a specific forum upon which to galvanize their beliefs and interests. Moreover, the 
mission and main messages of the ambassador organization were explicitly articulated and incorporated into the work that the students completed over the course of the workshop.

2. Students acquired and practiced concrete technical communication skills and strategies that would allow them to enact the role of the ambassador. A significant portion of the second and third day of the workshop was devoted to students gaining hands-on experience creating and practicing the delivery of a presentation. As a result, our participants reported that they gained technical skills and increased in their confidence to deliver presentations to different audiences. As a group, however, participants did not speak spontaneously about the generalizability of these skills.

3.The social structure and format of the workshop provided beginning ambassadors with ready access to role models who provided technical and social support. Social aspects of professional socialization were apparent in that the workshop was perceived as an opportunity for mentoring and networking with individuals from other universities. Structured and informal interactions provided students with role models whose behavior and skills could be emulated. The gathering also provided students with a sense of community among the ambassadors and, for those with new programs, a vision of what an established ambassador program could look like.

\section{Research Question 1. How do individuals' existing role identities inform the motivation to become an engineer-} ing ambassador? To become an engineering ambassador is to join an organization whose mission is to "change the conversation" about engineering in middle and high schools, using themes drawn from the NAE's Changing the Conversation (CTC) initiative. We hypothesized that there may be congruence between students' pre-existing professional goals and beliefs about engineering, and the ways in which CTC portrays engineering. Application of the themes of problems and solution messages revealed that five of the six participants spontaneously articulated professional goals that aligned with CTC solution messages, meaning that they were not provided with these messages nor were they prompted to describe them. Routinely, when asked to describe their goals for becoming an engineer, participants expressed a desire to use their careers to make a difference in the world, give back to their communities, or help others. One participant explicitly regarded articulation of CTC messages as a goal for their ambassadorship.

Hope, for example, stated that, given the skills and knowledge, she may "go around from country to country or wherever doctors are needed and apply it and help people..." Martha's professional goals included being able to "make a difference in either the environment or the public in general...to think my job would help someone..." Carla stated that she was "interested in water distribution or water quality...so something of that nature...I love to do mission trips." Alex's goals included being able to "use my skills... to help citizens in the community and give back." Only one participant, James, mentioned the professional goal of seeking leadership opportunities or other opportunities for professional development as one motivating factor in his decision to become an engineering ambassador.

We also investigated the question of whether, in their roles as engineering students and future engineers, participants' beliefs about the nature of engineering and its representation to the public would echo both the problems identified in $C T C$ and the associated solution messages. Three participants talked about issues relating to the reputation and public image of engineering and expressed beliefs that were aligned either with problem or solution-related messages. For example, James, an electrical engineering student, stated "I feel like there is this understanding that just because engineering is hard or it is considered hard, that we lose a lot of people to it." This statement was echoed by Hope in her interview, who said "people, when they think of engineering, they think you're supposed to be a genius and it's all hard work and math." In alignment with the theme that engineers contribute to the health, wellbeing and safety of society, Hope also identified the problem that people "don't see how it is applied to help people." Carla connected the solution message of a need for diversity to the engineering ambassadors' program mission. She described the goal as "Going out into schools and just helping other people to understand what engineering is, the different types of things to do as an engineer...just giving them a better understanding of what it is and why we need so many people, and diverse people, to be able to do this and just make the world a better place."

Roles manifested in the interview transcripts included engineering student, workshop participant, and engineering ambassador. Within the role of engineering student, statements about participants' own knowledge, interests, and personality characteristics were coded as self-perceptions, while statements about future plans were coded as goals. With varying degrees of specificity, all six participants articulated a vision of themselves as a professional in the field of engineering upon completion of their undergraduate degree.

Ambassadors perceived themselves as socially engaged future engineers. Activities matching with the mission of ambassadorship were seen as desirable and possible in participants' future careers. For some, the area was defined but the exact work was vague. Fisher, for example, described an interest in precious metals and gems. He stated that he wanted to know "how we could use these materials to be cheaper and actually use them to produce something better overall." Other participants described very specific future roles. For example, Hope articulated a desire to become a physician and to work in ways congruent with Doctors without Borders. James stated that he wants to "work in the nano 
industry...making components from the chemical perspective." The socially engaged engineering goals described by participants were related to their areas of existing knowledge and interest.

\section{Research Question 2. How did the role of workshop par-} ticipant shape the development of the ambassador role? Training provided a platform for workshop participants to share existing engineering-related knowledge and interests with others. There was strong alignment between engineering students' self-declared prior knowledge and existing interests, their ideas about their roles as future engineers, and their choice of presentation topic as workshop participants. Three of the six participants used areas of prior interest and expertise as the basis for their ambassador presentation. For example, Fisher chose 3D printing of musical instruments in part because he was a band member. James chose organic capacitors because he was working with a professor to conduct research in this area. Carla chose bio sand filters because she had previous knowledge of them from her mission trip.

Choices behind the presentation topic for two of the participants - Martha and Alex, whose presentation focused on 3D printing of inexpensive prosthetics - were less related to their prior interests, but were instead grounded in beliefs about what they (Martha) believed high school students would be interested in and beliefs (Alex) about the university administration's desire for outreach presentations to map onto its goal of sustainability. Only one participant, Hope, entered the workshop with very little prior knowledge about the topic of her presentation. However, she was paired with James, who led the technical aspects of the process, and who helped her find a topic where she could make a contribution. As it turned out, the topic did give her the opportunity to bring in her goal of using engineering to help others in under-developed countries.

The workshop created action possibilities for the participants in their roles as ambassadors. All of the participants mentioned the intention of giving an outreach presentation. Other action possibilities included creating a hands-on activity to accompany the presentation, and critiquing other ambassadors as they practiced their talks. Importantly, these new action possibilities were aligned with specific goals, beliefs, and self-perceptions reportedly held by the students before the workshop. Examples of alignment between various components of the initial ambassador role identity and the resulting action possibilities within that same role are shown in Table 3.

Research Question 3. Which features of the workshop emerged as the most powerful experiences for triggering the formulation of an Engineering Ambassador role identity? Two aspects of the workshop - the presentation skills training and the social context — were commented on by all six participants. Specifically, all commented on features of the workshop sessions in which they were given either direct instruction in presentation skills and techniques or, through critique sessions, feedback on their own presentations. One participant mentioned the direct instruction portions of the workshop but did not highlight the critique sessions. Table 4 presents quotes from each participant that reveal the impact of this aspect of the workshop on their role identities as presenters and as engineering ambassadors. Most frequent were impacts on self-perceptions and/or action possibilities as presenters.

Participants also talked about the social context of the workshop. Thematically, talking and networking with students from other schools and interacting with the senior ambassadors were mentioned all participants. Four out of six participants commented on their experiences of networking with students from other schools. For three of these students, their experiences impacted action possibilities in their role as either engineering ambassadors who develop and deliver presentations, or engineering student/future engineer. Carla commented that her senior ambassador mentor

"was really helpful...she helped us to organize our thoughts...how we would actually organize this presentation into three different parts that we could give it to a school...helping us to make things better before we even presented it."

As a graduating senior but founding member of the EA program at her school, Carla was impacted by the workshop's social context because it revealed features of programs elsewhere. Talking with other students and observing features of their programs led to a goal of trying to improve her own program. She said,

"It was good to see and get out there, out of the small college and get more involved and see what especially big schools like [university name] are doing in their engineering program that we could be implementing at our school, just trying to learn as much as we can I guess from these schools...it was helpful to see what kinds of programs they have...even though we are a lot smaller, just trying to be more involved... just get our program better for other students that are still coming through."

For Alex, interactions with senior ambassadors related to his plans to seek a summer internship. He stated, "I also liked meeting the senior ambassadors because they had a lot of expertise...they actually had experience in a professional engineering internship. I am looking to apply for a few internships this upcoming summer and I liked to hear their experienced with the companies they interned for." 
Table 3. Alignment among Ambassador Role Identity Components.

\begin{tabular}{|c|c|c|}
\hline Participant & Ambassador Role Identity Components & Example Action Possibility \\
\hline Alex & $\begin{array}{l}\text { " }<\text { Goal }>\text { Our school wanted to do outreach in the community } \\
\text { to make high school and middle school students really consider } \\
\text { engineering as an option because }<\text { Belief }>\text { we really need to } \\
\text { growth the profession in general...if it is not engineering at } \\
\text { [university name] if it is engineering in general, no matter where } \\
\text { they go }<\text { Goal }>\text { we want to give them an interest in engineer- } \\
\text { ing." }\end{array}$ & $\begin{array}{l}\text { "Establish the EA network as } \\
\text { a leadership opportunity...I will probably be partici- } \\
\text { pating as a senior ambassador as a junior and senior...I } \\
\text { will go out to the high schools in the area and give our } \\
\text { presentations." }\end{array}$ \\
\hline Fisher & $\begin{array}{l}\text { " }<\text { Self-perceptions }>\text { I run the tour program right now as a co-di- } \\
\text { rector, and some of the presentations, nit- picky things I didn't } \\
\text { know about, and now }<\text { Self-perceptions }>\text { I can actually do this } \\
\text { and critique people and actually }<\text { Belief }>\text { make them a better } \\
\text { presenter." }\end{array}$ & $\begin{array}{l}\text { "An awesome opportunity to } \\
\text { learn how to make a presentation, give a presentation and } \\
\text { how to critique someone giving a presentation..." }\end{array}$ \\
\hline James & $\begin{array}{l}\text { " }<\text { Self-perceptions }>\text { I kind of agree with the whole message of } \\
\text { the program...I feel like going to schools, especially specific } \\
\text { neighborhoods around here (that need) some redevelopment and } \\
\text { I feel like }<\text { Belief }>\text { there is probably plenty of smart kids and a } \\
\text { job in engineering could probably help them out quite a bit or } \\
\text { people might not have even thought about it and they probably } \\
\text { could help make the next big thing... more people need to know } \\
\text { about it. }<\text { Belief }>\text { I feel like it is important." }\end{array}$ & $\begin{array}{l}\text { "Try to get samples from } \\
\text { advisor" (to develop the hands-on activity) } \\
\text { "we are going to be trying to go into one or two schools } \\
\text { in the next few weeks" }\end{array}$ \\
\hline Carla & $\begin{array}{l}\text { "What can we do at our school to try to }<\text { Goal }>\text { make this } \\
\text { program grow?" } \\
\text { "going out to schools and just }<\text { Goal }>\text { helping other people to } \\
\text { understand what engineering is, the different types of things to } \\
\text { do as an engineer...I think just giving them a better understand- } \\
\text { ing of what it is and why }<\text { Belief }>\text { we need so many people, and } \\
\text { diverse people, to be able to do this and just make the world a } \\
\text { better place." }\end{array}$ & $\begin{array}{l}\text { "A big takeaway...being involved } \\
\text { as much as we can...get out there and see what big } \\
\text { schools are doing in their engineering program that we } \\
\text { could be implementing at our school..." } \\
\text { "we definitely do plan on using them" (the presentations) }\end{array}$ \\
\hline Hope & $\begin{array}{l}\text { " }<\text { Goal }>\text { if I got into this program and I create a presentation to } \\
\text { go out and help talk about engineering that helps them (students) } \\
\text { think that it (engineering) is an option, and they may like it, why } \\
\text { not?" }\end{array}$ & "We have plans throughout this month to go to schools." \\
\hline Martha & $\begin{array}{l}\text { " }<\text { Belief }>\text { It is not just about math and science but... having the } \\
\text { passion to help others...I just really hope that it gets students } \\
\text { excited. It's not like another boring presentation coming in. } \\
<\text { Goal }>\text { I want them to be having fun and have a good activity } \\
\text { with me and just get them interested in the field of engineering." }\end{array}$ & $\begin{array}{l}\text { "We want to present our topic to } \\
\text { the freshmen and hopefully get them interested and } \\
\text { recruit them to become a part of the network...next year } \\
\text { I will be a senior ambassador and I will mentor all the } \\
\text { new ambassadors...by next semester we can actually go } \\
\text { out to local high schools and middle schools and present } \\
\text { our topics." }\end{array}$ \\
\hline
\end{tabular}

Two participants described gaining a sense of community and shared goals from interacting with students from other programs. Alex stated that he "loved meeting new people... loved seeing the other engineering programs around the country." When he sat with other students, they "compared and contrasted our engineering programs," but while their programs differed,

We didn't have much differences... when I talked with other students from different universities, we all shared a common goal about wanting to help people in our professional careers and gain skills to just make the world a better place.

Fisher stated that a highlight of the workshop was "get- ting to meet some of these people (other students)...we all have something in common...get people to learn about STEM projects and trying to become better presenters and better people in the STEM community, ourselves." The social context and the broader experience of the workshop seemed to have a deeper impact on his self-perceptions and his professional goals. In response to a question about what he would take away from the weekend, he described that he had gained new skills, saying

I run the tour program right now as a co-director, and some of the presentations, nitpicky things I didn't know about, and now I can actually do this and critique people and make them a better presenter and actually make presentations. 
Table 4. The impact of presentation development work on participants' role identities as presenters and engineering outreach ambassadors

"We sat through a presentation on public speaking... and how we organize a presentation that was great. I really loved that because that gave me a new perspective on formatting a presentation that can get the topic across to the audience without distracting

AP, Presenter

Alex or boring them."

"I felt a lot more confident in my presentation skills to be honest. I feel accomplished...By the end of the workshop, having a presentation that was really geared

SP, Presenter towards high schoolers and can really get them interested in engineering. I was really proud to be a part of that."

\& Engineering Ambassador

(before) "I didn't know what was the mapping slide.

Assertions, I know how long it has to be, how to insert a video..."

AP, Presenter

Fisher

"awesome opportunity to learn how to make a presentation, how to give presenta- $\quad$ AP, tions, and how to critique someone...I actually used it yesterday"

Engineering Ambassador

"I learned about my strengths and weaknesses as a presenter...I am very passionate but I also learned I have a tendency to get way into it... Being aware of my shortcomings I increased my confidence... because I know what to avoid and I know I can turn

SP, Presenter

James it around.”

"how to make this presentation as good as you could before you would take it out and actually present it to a group of stu-dents...I would say getting more comfortable

Carla presenting it...we kind of saw our presentations didn't measure up to the other ones and we were able to present it...just getting more confidence, we were able to go out and do this and do it well."
SP, Presenter

\& Engineering Ambassador

"I learned that you don't need a lot of words to make someone understand what you are saying."

Hope

"You can use pictures and have a sentence or two...you also have to rehearse in your

AP, Presenter head...you have to choose something you like to do."

"they gave us a lot of time to work on it (the presentation) and I just felt really prepared and I thought the workshop really boosted my confidence in public speaking because I am not the type of person who loves public speaking but you know after the presenta-

SP, Presenter tion on Sunday I felt really good about myself and how I presented."

$A P=$ Action Possibilities; $S P=$ Self-Perceptions

When asked about his future role as an engineering ambassador at his school during the upcoming school year, he revealed how the workshop and his experiences afterwards had impacted his goals. He said,

That's a complicated question. I really don't know... joined the ambassadors because I was interested in the program. I didn't know how big engineering ambassadors was and I got to meet the people actually inside the program and outside in the engineering ambassadors community...I guess this workshop helped me pinpoint what I want to do, it's kind of different from what I first wanted to do and I'm thinking of becoming a teacher...I like to give people advice and I guess I like to be there for a person and try to make them a better person, like lead them to success and if I can do that with teaching or as an engineer in general, in the industry, that's what I want to do.

Fisher pointed to an experience that revealed a perception of the engineering ambassadors as a community. He said,

I was just talking to a couple of junior engineering ambassadors, they're new... about their personal life and how they see college and they see me now as a role model, as a mentor. It's funny how that all works out and through engineering ambassadors...people come on tours...they ask us questions and just seeing their expressions...in their e-mails it's like they want to learn more, it's like they actually want to become part of this community we have created.

\section{DISCUSSION}

This case study with embedded units examined the role 
identities of six undergraduate engineering students who participated in an event designed to train them to fulfill the technical communication portion of the engineering ambassador role. Our theoretical framework was deliberately inclusive of previously separate cognitive, social and cultural perspectives on professional identity formation, and yielded an analysis of self-perceptions, goals, beliefs and action possibilities in existing and newly emerging social roles. Interviews revealed the existence of role identity components in the role of engineering student/future engineer, workshop participant, and (emerging) engineering ambassador, anchored in the sub-role and associated action possibilities of presenter.

Our first research question investigated how components of individuals' role identities aligned to inform the motivation to become an engineering ambassador. Becoming an ambassador entails a commitment to extra-curricular tasks that include communication of solution-oriented messages included in, but not limited to, the messages presented in the NAE document Changing the Conversation. A solution message is therefore one that is designed to promote understanding about engineering where a problematic lack of knowledge and understanding, or a misconception, may exist among the audience. Message communication is often embedded within activities that consciously reach out to young audiences and under-represented groups in order to educate and excite them about the field of engineering.

We found that participants' existing goals, beliefs, and self-perceptions were congruent with those necessary to fulfill the role of engineering ambassador. Five out of the six individuals articulated professional goals congruent with messages that have been found to be effective in encouraging diverse groups to consider engineering as a career choice such as using their skills to benefit others, or working in a professional setting that would allow them to contribute to the health, wellbeing and safety of others. Similarly, solution messages that target noted problems faced by the field of engineering in terms of public perception of the field, including misunderstandings about what engineers do and lack of interest in pursuing engineering as a career option, were mentioned spontaneously by three of the six participants in the context of talking about why they chose to become involved in the organization. One participant mentioned that he had repeatedly come across other people with misperceptions of his chosen field of electrical engineering. All six participants expressed either a desire or a commitment to pursuing an engineering-related career, and four individuals explicitly integrated socially engaged activities that are congruent with Changing the Conversation solution messages into their career plans.

Together, these three factors - existing professional goals aligned with the organization's mission, beliefs about problems faced by engineers aligned with the problem that or- ganization-related activities are designed to overcome, and an emerging commitment to pursuing an engineering-related career-demonstrate ways in which existing beliefs and goals informed all participants' experiences of the training workshop. Participants also brought topic related aspects of their existing role identities into the training context. For example, students' content area expertise and interests as undergraduate engineering students (e.g. bio sand filters, 3D printing of musical instruments, organic capacitors) often became the topic of their outreach presentations. Thus, students leveraged their existing identities as undergraduate engineering students to shape their initial foray into the ambassador role.

Participants' statements about intentions and planned activities in their new role as engineering ambassadors were positioned as action possibilities. Aligned with these were goals about what they and their peers could accomplish as ambassadors, and beliefs about the purpose and importance of ambassadorial work. Action possibilities were often fairly vague, perhaps because of the brief nature of the workshop intervention, and the fact that the interview was conducted prior to actual ambassadorial work and hence too early for the articulation of personal qualities that could be coded as self-perceptions as an ambassador such as being a good speaker, or someone who effectively engages younger students. Participants did not make statements that revealed misalignment, or tension, among their self-perceptions, goals, beliefs, and action possibilities. Other research examining role identity change during professional development workshops has detected misalignments among components, but has found that this is more likely in contexts where action possibilities are more tightly constrained than in the present context, such as when teachers discuss their perceived options for working in formal school settings (Hathcock, 2014), or when undergraduate students feel that they have to choose between other school work and ambassador visits (Garner et al., 2017).

More notably impacted were participants' self-perceptions in the role of presenter. All of the students made statements about how the training impacted their perceived ability, confidence and in some cases their self-awareness in relation to strengths and weaknesses they possessed. Positive impact on students' self- perceptions about presentation skills was evident when participants were asked to relay highlights or successes from the workshop. Participants spoke of their new skills and confidence in their ability to present information and attached these to multiple roles including ambassador, undergraduate student, research assistant, and intern. Findings of confidence in communication skills echoes the outcomes of other programs that have involved science graduate students in educational outreach activities (Abt Associates, Inc., 2010), although our study is limited to demonstrating that this self-perception can occur early on in students' training. 
Specific features of the training context seemed to promote the ambassador role identity. Instruction on presentations and opportunities to present and receive feedback in a supportive, peer-filled environment were associated with the development of specific action possibilities in the roles of presenter and future engineering ambassador. In addition, students' action possibilities in relation to their home institution's program and their own future careers were impacted by the opportunity to network with students from other institutions. Learning how to create and deliver a presentation that used a particular format and message, learning to critique others within a social context of shared goals about the purpose of the engineering ambassadors program, and learning to interact with other, like-minded undergraduate students seemed to spur participants to formulate individual or program-level goals about sustaining ambassadorship at their institution. For two participants, presentation training and social interactions were linked with intentions to becoming a mentor within the ambassador organization and beyond.

Significance. This study, although small in scale, provides a detailed and theoretically situated analysis of the process of becoming a STEM outreach ambassador. Examining the process through the theoretical lens of role identity theory allowed us to extract and populate the identity components of three separate but intimately connected and mutually reinforcing roles: student, participant, and ambassador. Interestingly, the sub-role of presenter emerged as an important bridge between these roles. Presentation topics were often derived from students' interests and self-perceptions of expertise in particular areas. Immediate action possibilities in the presenter role, such as public speaking, were linked to future action possibilities and positive self-perceptions about fulfilling the roles of ambassador and student. As students, beliefs about engineering and the misconceptions held by the public were aligned with goals for their work in the role of ambassador. Finally, as students, participants valued the role of ambassador, either because they themselves wished they had been exposed to such role models and messengers, or because they had been fortunate to benefit from this type of mentorship and interaction when they were younger. In total, our findings suggest that the process of becoming an ambassador was a relatively familiar next step for participants and did not involve the acquisition of an unfamiliar role. This finding is congruent with previous work by Lichtfield and Javernick-Will (2015), Tate and Linn (2005), and Craig (2013), who have found an alignment between ethnic and demographic features of outreach-engaged students and the inclusive mission of the organizations in which they were involved, and an alignment between students' thinking about the content of their discipline and their emerging identities as engineers.
Participants' narratives revealed that the process of role identity development involves psychological components and social processes, and that these processes are evident in engineering students as they experience the journey through formal education towards a professional career (Holmegaard et al., 2014; Ibarra, 1999). This is congruent with the DSMRI, which holds that individuals' psychological realities are closely connected to the social context in which these realities are experienced. One example of this intersection is the workshop, rather than outreach, context. Students described personal gains in confidence and technical skill from being mentored by senior ambassadors, but also focused on the process of presentation skill acquisition rather than ambassador role development. This finding suggests that the workshop context, although useful and beneficial for presentation training, may not promote full ambassador role development. For students to more comprehensively adopt the ambassador role, on-the-job training or visit observations may be required. Therefore, one implication of this study is the need to consider training and ambassador role identity development as an ongoing process. Over time, the role may become more differentiated from other roles including undergraduate student and presenter. It may fluctuate in its alignment with these roles and may even conflict at times, for example if the student has to balance coursework with commitments to providing outreach visits. At such times, the salience or relative importance of each particular role may shift. Understanding how role salience changes over time in response to life events and contexts may promote strategies for retaining ambassadors and supporting them throughout their undergraduate career. It may also offer insights into ambassadorship as an intervention, and explore its potential for outreach activities to change students' understanding of how engineering can tackle social issues or shift students' beliefs about the implications of broadening participation in STEM fields as a whole.

Limitations. Due to the small number of interviews that were included in the analysis, and the single time point for data collection, it is worth noting that the findings may have limited generalizability to the way that role identity development manifests in other participants. Furthermore, the data cannot speak predictively to participants' behaviors once in the role of ambassador at their home institutions. To draw conclusions about the degree to which initial role identity formation processes impact later perceptions and behaviors, future research should utilize a longitudinal design or a larger scale, cohort approach.

A second limitation is the reliance of the study on self-report data in the absence of additional observational data or the analysis of the products of the students' efforts. Although our epistemological perspective embraced the validity of individuals' subjective experiences as a valid form 
of data (Moustakas, 1994), future research in this area may benefit from more systematic observations of the training experience or stimulated recall using video from training or outreach events (Creswell and Miller, 2000). Future avenues of inquiry might investigate different forms of training events and compare ways in which an ambassador role identity might emerge from, for example, training in hands-on activity creation or the delivery of "tour guide" style talks.

\section{CONCLUSION}

This research is significant in its focus on undergraduate students' professional development rather than on the impact of visits on K-12 audiences. Our findings point to the dynamic and parallel nature of role identity development and the capacity for even short workshop events like the one in which our participants were enrolled to result in changes to undergraduate students' self-perceptions, beliefs, goals, and possibilities for future action.

Participants' descriptions of their experiences revealed that they moved fluidly among roles over the course of the workshop, depending on the situation and its demands. Students left the workshop with an ambassador role that, although under construction, seemed very much connected to their present-day role identities as undergraduate students and future engineers. Ongoing support may be needed to facilitate integration of the new presenter and ambassador roles into existing roles of engineering student, particularly as the students move through their undergraduate curriculum, prepare to graduate into the workforce and assume new professional identities as engineers, and more immediately, as they navigate practical dilemmas such as competing constraints on their time (role-based actions).

In future, evaluations of outreach ambassador programs might even include data about the long term impact on the professional development of undergraduate students, with a view to tracking students' commitments to the field of engineering once in the workplace. Such data may offer insights into the nature of the "return on investment" for ambassadors, their universities, and their subsequent employers.

\section{AUTHOR INFORMATION \\ Corresponding Author}

Joanna Garner, jkgarner@odu.edu. The Center for Educational Partnerships. Old Dominion University.

\section{Author Contributions}

The manuscript was written through contributions of all authors. All authors have given approval to the final version of the manuscript.

\section{ABBREVIATIONS}

CTC: Changing The Conversation; STEM: Science, technology, engineering, and mathematics.

\section{REFERENCES}

After School Alliance (2011). STEM Learning in Afterschool: An Analysis of Impact and Outcomes. Retrieved from www. afterschoolalliance.org/STEM-Afterschool-Outcomes.pdf

Abt Associates, Inc. (2010). Evaluation of the National Science Foundation's GK-12 Program: Final Report Volume I and II: Technical Report and Appendices. Retrieved from http://bit.ly/YfEZhz

Allie, S., Armien, M.N., Burgoyne, N., Case, J.M., Collier-Reeds, B.I., Craig, T.S., Deaon, A., Fraser, D.M., Geyer, Z., Jacobs, C., Jawitz, J., Kloot, B., Kott, L., Langdon, G., le Roux, K., Marshall, D., Mogashana, D., Shaw, C., Sheridan, G., and Wolmarans, N. (2009). Learning as acquiring a discursive identity through participation in a community: improving student learning in engineering education. European Journal of Engineering Education, 34(4), 259-267.

Anagnos, T., Lyman-Hold, A., Marin-Artieda, C. and Momsen, E. (2014). Impact of engineering ambassador programs on student development. Journal of STEM Education: Innovations and Research, 15(3), 14-20.

Baxter, P., and Jack, S. (2008). Qualitative case study methodology: Study design and implementation for novice researcher. The Qualitative Report, 13, 544-599.

Bergeson, A.A., Hotchkins, B.K., and Furse, C. (2010). Outreach and identity development: New perspectives on college student persistence. Journal of College Student Retention: Research, Theory and Practice, 16(2), 165-185.

Burke, P.J. (2006). Identity change. Social Psychology Quarterly, 69(1), 81-96.

Burke, P.J., and Reitzes, D.C. (1991). An identity theory approach to commitment. Social Psychology Quarterly, 54(3), 239251 .

Burke, P.J., and Harrod, M.M. (2005). "Too much of a good thing?" Social Psychology Quarterly, 68, 359-374.

Buse, K., Bilimoria, D., and Perelli, S. (2013). Why they stay: Women persisting in U.S. engineering careers. Career Development International, 18(2), 139-154.

Chachra, D., Kilgore, D., Loshbaugh, H., McCain, J. and Chen, H. (2008). Being and becoming: Gender and identity formation of engineering students. Proceedings of the American Society for Engineering Education 118thAnnual Conference and Exposition, Vancouver, CA.

Craig, T.S. (2013). Conceptions of mathematics and student identity: implications for engineering education. International Journal of Mathematical Education in Science and Technology, 44(7), 1020-1029.

Creswell, J.W. (2013). Five approaches to qualitative inquiry. In J. W. Creswell (2013) Qualitative inquiry and research designs: choosing among five different approaches. (pp.69110). Thousand Oaks, CA: Sage Publications. 
Creswell, J.W., and Miller, D.L. (2000). Determining validity in qualitative inquiry. Theory into Practice, 39(3), 124-130.

Erikson, E. H. (1968). Identity, Youth and Crisis. New York: W.W. Norton and Company.

Garner, J.K., Alley, M., Haas, C., Sontgerath, S., and Kaplan, (2017). Developing a role identity as an ambassador through hands-on activities. Presented at the annual meeting of the American Society for Engineering Education, Columbus, Ohio.

Garner, J.K., Alley, M., Haas, C. and Kaplan, A. (2016). From undergraduates to ambassadors: The impact of Engineering Ambassador training. Presented at the annual meeting of the American Society for Engineering Education, New Orleans, LA.

Garner, J.K., and Alley, M. (2013). How the design of presentation slides affects audience comprehension: A case for the assertion-evidence approach. International Journal of Engineering Education, 29(6), 1564-1579.

Gunersel, A.B., Kaplan, A., Barnett, P., Etienne, M., and Pollock, A. (2016). Profiles of change in motivation for teaching in higher education at an American research university. Teaching in Higher Education, 21, 628-643.

Habash, R., and Suurtamm, C. (2010). Engaging high school and engineering students: A multifaceted outreach program based on a mechatronics platform. IEEE Transactions on Education, 53(1), 136-143.

Hathcock, S. (2014). Professional Identity and Pedagogical Discontentment in High School Science Teachers Participating in a Professional Development Institute. Unpublished doctoral dissertation. Norfolk, VA: Old Dominion University.

Hazari, Z., Sadler, P.M., and Sonnert, G. (2013). The science identity of college students: Exploring the intersection of gender, race, ethnicity. Journal of College Science Teaching, $42(5), 82-91$.

Heffernan, K. (2016). Promoting preservice teachers' mathematics identity exploration. Unpublished doctoral dissertation. Philadelphia, PA: Temple University.

Holmegaard, H.T., Madsen, L.M., and Ulriksen, L. (2014). A journey of negotiation and belonging: understanding students' transitions to science and engineering in higher education. Cultural Studies in Education, 9, 755-786.

Hsieh, H.F., and Shannon, S.E. (2005). Three approaches to qualitative content analysis. Qualitative Health Research, 15(9), 1277-1288.

Ibarra, H. (1999). Experimenting with image and identity in professional adaptation. Administrative Science Quarterly, 44(4), 764-791.

Jawitz, J., and Case, J. (1998). Exploring the reasons South African students give for studying engineering. International Journal of Engineering Education, Vol. 14, no. 4, pp.235240.

Kaplan, A. and Garner, J.K. (2017). A complex dynamic systems perspective on identity and its development: The Dynamic Systems Model of Role Identity. Developmental Psychology, 53(11), 2036-2051.
Kaplan, A., and Garner, J.K. (n.d.). Dynamic Systems Model of Role Identity (DSMRI): Analysis guide and codebook.

Lichtfield, K., and Javernick-Will, A. (2015). "I am an engineer AND": A mixed methods study of socially engaged engineers. Journal of Engineering Education, 104(4), 393-416.

McAdam, D., and Paulsen, R. (1993). Specifying the relationship between social ties and activism. American Journal of Sociology, 99(3), 640-667.

Molina-Gaudo, P., Baldassarri, S., Villarroya-Gaudo, M., and Cerezo, E. (2010). Perception and intention in relation to engineering: A gendered study based on a one-day outreach activity. IEEE Transactions on Education, 53(1), 61-70.

Moskal, B. and Skokan, C. (2011). Supporting the K-12 classroom through university outreach. Journal of Higher Education Outreach and Engagement 15(1), 53-75.

Moustakas, C. (1994). Phenomenological Research Methods. Thousand Oaks, CA: Sage.

Nadelson, L., and Callahan, J. (2011). A comparison of two engineering outreach programs for adolescents. Journal of STEM Education, 12(1), 43-54.

NAE (2008). Changing the Conversation: Messages for Improving Public Understanding of Engineering. Washington, D.C.: National Academy of Engineering Press.

Nino, L.S., (2013). Precursors of professionalism in college seniors: Influence of major, gender, and institution. Research in Higher Education Journal, 21, 1-20.

Nystrom, S. (2009). The dynamics of professional identity formation: Graduates' transitions from higher education to working life. Vocations and Learning, 2, 1-18.

Orsak, G.C. (2003). Guest editorial. K-12: Engineering's new frontier. IEEE Transactions on Education, 46(2), 209-210.

Oyserman, D., Bybee, D., Terry, K. and Hart-Johnson, T. (2004). Possible selves as roadmaps. Journal of Research on Personality, 38, 130-149.

Papafilippou, V., and Bentley, L (2017). Gendered transitions, career identities and possible selves: the case of engineering graduates. Journal of Education and Work, 30(8), 827-839.

Penuel, W.R., and Wertsch, J.V. (1995). Vygotsky and identity formation: A sociocultural approach. Educational Psychologist, 30(2), 83-92

President's Council of Advisors on Science and Technology (2010). Report to the President: Prepare and Inspire: K-12 Education in Science, Technology, Engineering and Math (STEM) for America's Future. Retrieved from https:// obamawhitehouse.archives.gov/sites/default/files/microsites/ostp/pcast-stem-ed-final.pdf

Reitzes, D.C., and Mutran, E.J. (1995). Multiple roles and identities: Factors influencing self-esteem among middle-aged working men and women. Social Psychology Quarterly, 57(4), 313-325.

Sahin, (2013). STEM clubs and science fair competitions: Effects on post-secondary matriculation. Journal of STEM Education: Innovations and Research, 14(1), 5-11. 
Serpe, R.T., and Stryker, S. (1987). The construction of self and the reconstruction of social relationships. In E.J. Lawler and B. Markovsky (Eds.). Advances in group processes: Theory and research (Vol. 4, pp.41-82). Greenwich, CT: JAI Press.

Smaill, C.R. (2010). The implementation and evaluation of a university-based outreach laboratory program in electrical engineering. IEEE Transactions on Education, 53(1), 12-17.

Stake, J.E. and Mares, K.R. (2001). Science enrichment programs for gifted high school girls and boys: Predictors of program impact on science confidence and motivation. Journal of Research in Science Teaching, 38(10), 1065-1088.

Stake, R. E. (1995). The Art of Case Study Research. Thousand Oaks, CA: Sage.

Steinke, J. (2017). Adolescent girls' STEM identity formation and media images of STEM professionals: Considering the influence of contextual cues. Frontiers in Psychology, 8, $1-15$.

Tate, E.D., and Linn, M.C. (2005). How does identity shape the experiences of women of color engineering students? Journal of Science Education and Technology, 14(5-6), 483-493.

UNESCO, (2010). Engineering: Issues, Challenges, and Opportunities for Development. Retrieved from http://www. unesco.org/new/en/natural-sciences/science-technology/ engineering/engineering-education/unesco-engineering-report/

Wei, S., and Wonch Hill, T. (2018). An evaluation on engineering identity of K-12 youth using the Engineering Ambassador Network. Presented at the Annual Meeting and Exposition of the American Society for Engineering Education, Salt Lake City, UT.

Yin, R.K. (2002). Case Study Research: Design and Methods. Sage Publications.

Zhang, Y., and Wildemuth, B.M. (2009). Qualitative analysis of content. In B.M. Wildemuth (Ed.), Applications of Social Research Methods to Questions in Information and Library Sciences. Pp. 1-12. 